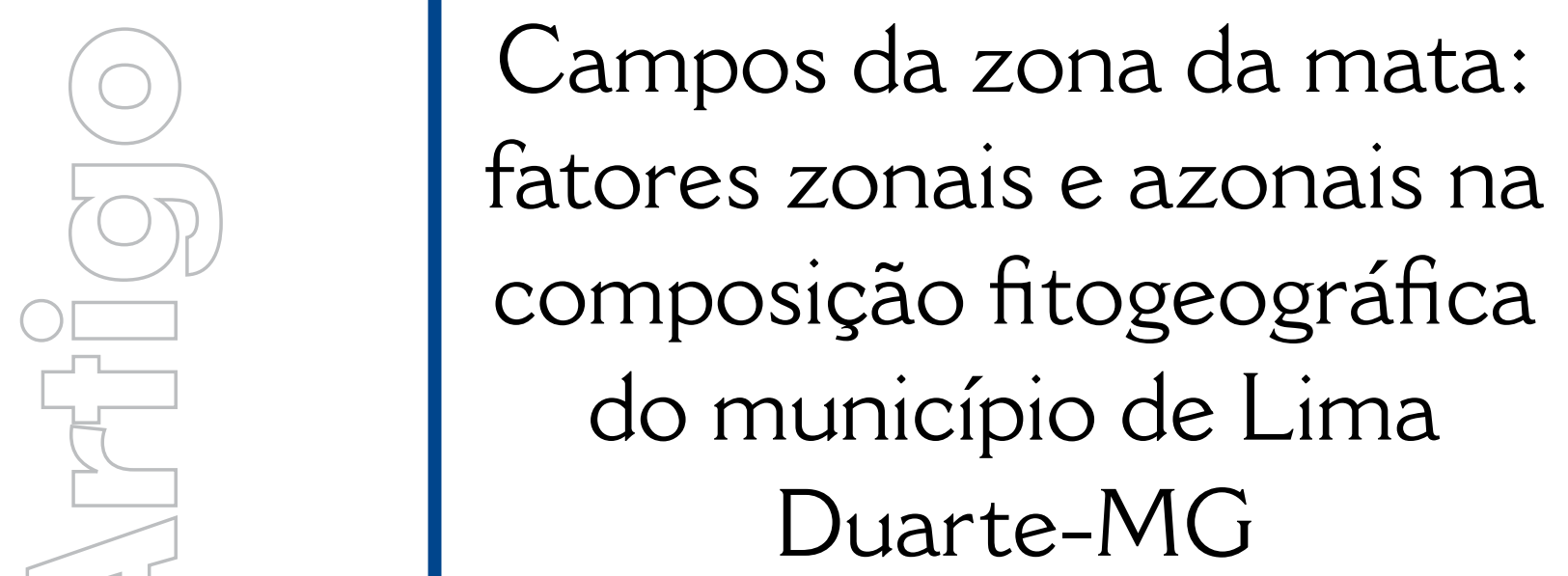

revista

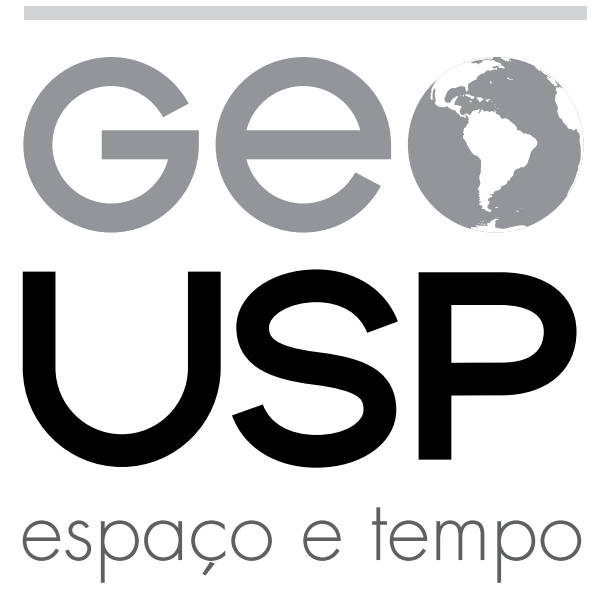

Volume $21 \cdot \mathrm{n}^{\circ} 1(2017)$

ISSN 2179-0892
Roberto Marques Neto

UFJF

p. $198-216$

Como citar este artigo:

MARQUES NETO, R. Campos da zona da mata: fatores zonais e azonais na composição fitogeográfica do município de Lima Duarte-MG. Geousp - Espaço e Tempo (Online), v. 21, n. 1, p. 198-216, abril. 2017. ISSN 2179-0892.

Disponível em:

$<$ http://www.revistas.usp.br/geousp/article/view/108037> . doi: 10.11606/issn.2179-0892.geousp.2017.108037.

\section{(c) (i) \$)}

Este artigo está licenciado sob a Creative Commons Attribution 4.0 License. 


\title{
Campos da zona da mata: fatores zonais e azonais na composição fitogeográfica do município de Lima Duarte-MG
}

\section{Resumo}

No domínio tropical atlântico, uma série de unidades de paisagem se consubstancia a partir da intersecção entre elementos zonais e azonais, existindo em meio a cinturões florestais uma série de fisionomias vegetais campestres na forma de redutos em condição de enclave forjado pela altitude elou fatores edáficos. A partir dessa premissa, este trabalho discute o quadro fitogeográfico do município de Lima Duarte, localizado na porção sudeste da Zona da Mata Mineira, numa abordagem geoecológica, correlacionando as manifestações fitofisionômicas com a litologia, o relevo, os solos e elementos climáticos. Indubitavelmente, é na conjugação desses fatores que se podem interpretar as diferentes formações florestais e campestres que ainda coexistem com as formas vigentes de uso da terra.

Palavras-chave: Campos rupestres. Campos altimontanos. Cristas quartzíticas. Lima Duarte.

\section{Zona da Mata fields: zonal and azonal factors in the fitogeographic composition on the city of Lima Duarte (MG)}

\begin{abstract}
In the Atlantic tropical domain a series of landscape unities is consolidated from the intersection between zonal and azonal elements existing among the forestry belts a series of rural vegetable physiognomies in the shape of strongholds in condition of enclave forged by altitude and/or edaphic factors. From such premise the present paper objectivates on discussing the fitogeographic frame in the city of Lima Duarte located in the southeastern portion of Zona da Mata of Minas Gerais from a geoecological approach
\end{abstract}


correlating the fitophisionomic manifestations with the lithology, relief, soil and climatic elements. Doubtless in the conjugation of such factors is where it makes the interpretation about the occurrence of the different forestry and rural formations that yet coexist with the present ways of ground usage practicable.

Keywords: Rocks fields. High altitude fields. Quartzitic combs. Lima Duarte.

\section{Introdução}

Com frequência a designação de localidades e a transmissão de conhecimentos acerca de uma determinada área são condutas que se pautam no uso de toponímias, empregadas com base na vegetação, na fauna, em morfoesculturas geográficas e outros atributos naturais que muitas vezes refletem estruturas e dinâmicas pretéritas de paisagens já significativamente transformadas pelas atividades humanas. $O$ que dizer da expressão indígena catanduva, que dá nome a um município situado no oeste do estado de São Paulo, e que designa um tipo de mata seca (Rizzini, 1979), semelhante a um cerradão? Certamente faz alusão à presença dessa fisionomia vegetacional na região anteriormente ao avanço da cultura do café, das malhas ferroviárias, rodoviárias e urbano-industriais, informando acerca da cobertura vegetal pretérita em uma região onde as referências fitofisionômicas e florísticas sofreram depleção quase total há décadas. A Floresta Ombrófila Mista, mata com araucária (Araucaria angustifolia), já não domina as paisagens da região onde se localiza o município a sudoeste de Curitiba nominado a partir desta árvore (Araucária-PR), em declarada inspiração nesse pinheiro outrora profuso nos três planaltos paranaenses e por todo o Planalto Meridional. Acerca das relações entre a vegetação e a nomenclatura de certas localidades e espacialidades, seja de um lugar, de uma região, ou de um fenômeno do relevo, os exemplos sobejam e compõem uma farta listagem.

A designação Zona da Mata, em referência a uma mesorregião de planejamento no sudeste de Minas Gerais, sinaliza explicitamente que a vegetação original é composta por diferentes fitofisionomias florestais do domínio tropical atlântico, malgrado as florestas típicas dos cinturões quentes e úmidos não mais constarem como variáveis dominantes na paisagem, exceção feita aos setores de relevo acidentado desafiadores à ocupação humana e às áreas protegidas. As coberturas florestais nativas, inequivocamente predominantes na região da Zona da Mata, não constituem os únicos grupos fitofisionômicos existentes, sendo relativamente comuns os enclaves de campos altimontanos influenciados pela elevação topográfica (e variações climáticas associadas) e por fatores edáficos e litológicos. Aparecem nos compartimentos elevados que perfazem os principais interflúvios, ou sobre rochas quartzíticas comuns na região, substrato que dá suporte a fitofisionomias 
eminentemente rupestres. Por vezes, essas coberturas vegetais são homenageadas na toponímia dos lugares e fincam raízes na oralidade pela qual a informação é transmitida ao longo de sucessivas gerações.

O extremo sul da Zona da Mata Mineira estabelece importantes conectividades florestais com a região meridional do estado, inserindo-se assim no corredor ecológico da Serrada Mantiqueira, queresguardaremanescentes florestais dodomínio tropical atlântico em seus relevos de cristas alongadas escarpadas e vales profundamente dissecados. Em tal contexto, se inscreve o município de Lima Duarte, cujo perímetro territorial comporta relevos em cristas festonadas inclusas nos corredores supramencionados, dando aporte tanto a fisionomias florestais como a campos rupestres e altimontanos, sendo que seu território comporta ainda a maior parte de uma unidade de conservação de proteção integral (Parque Estadual do Ibitipoca). Avulta para Lima Duarte, dessa maneira, um significativo valor ecológico (dado pelas conectividades funcionais que perpassam o território municipal) e biogeográfico, plenamente justificado pelas diferentes fisionomias campestres sui generis que, em certa medida, se arranjam na conformação de autênticas paisagens de exceção na acepção de Ab'Sáber (2006). Esse conjunto de justificativas motivou a interpretação do quadro fitogeográfico de Lima Duarte (MG), discutindo as relações da vegetação com o clima (pretérito e atual), com o substrato (litologia, relevo e solos) e com o ritmo e formas de ocupação humana, sendo seus resultados gerais apresentados no escopo do presente artigo.

\section{Concepção teórica e procedimentos metodológicos}

Os pressupostos teórico-metodológicos que patrocinaram a interpretação aqui divulgada têm como fundamento a abordagem sistêmica (Bertalanffy, 1973), inclinandose para um estudo da vegetação no âmbito das organizações espaciais que operam no conjunto da paisagem conformando sua estrutura e dinâmica a partir de um enfoque geoecológico aplicado à biogeografia. Em caráter mais específico, buscou-se interpretar a correlação entre os elementos zonais e azonais na diferenciação dos territórios e composição das paisagens regionais, postura esta delineada por Isachenko (1973) como concepção metodológica seminal no estabelecimento de sínteses naturalistas e regionalizações físico-geográficas. Segundo o autor, zonalidade e azonalidade figuram como os dois princípios gerais de diferenciação territorial a partir de uma perspectiva genético-estrutural. Ainda na perspectiva zonal lazonal, Walter (1984) interpenetrou os fatores azonais em sua classificação dos domínios vegetais do orbe construída a partir da zonalidade climática e fatores hidrotérmicos associados, inserindo nos chamados zonobiomas manifestações de orobiomas, litobiomas e pedobiomas, agrupamentos bióticos que ocorrem em controle exercido pelo relevo, litologia e solos, respectivamente. No contexto brasileiro, destaca-se a notória classificação proposta por Ab'Sáber (1977, 2003) para os domínios de natureza do Brasil, e que também toma por princípio os fatores zonais e azonais, apresentando elementos da proposta de Walter (1984) associada aos conceitos de geossistema e ecossistema. Com isso, o insigne geógrafo reconhece 
as famílias de ecossistemas predominantes vinculadas ao domínio morfoclimático em questão coexistindo com ecossistemas de enclave, na forma de mini e mesorredutos de significado paleoclimático ou determinado por condições locais ou regionais do geossistema. Para a região da Serra do Catimbau, no nordeste semiárido, Cavalcanti (2013) também utilizou essa concepção integrada, orientada a um proficiente esquema regional pautado na abordagem geossistêmica.

Remissão a uma literatura básica e específica sobre a vegetação no setor da Zona da Mata Mineira de maior interesse (Dias, 2000; Valente; Garcia; Salimena, 2006; Abreu; Santiago; Menini Neto, 2007; Monteiro; Forzza, 2008; Dutra; Salimena; Meinini Neto, 2012; Oliveira Filho et al., 2013), campanhas de campo, interpretação e classificação de imagens de satélite para o mapeamento da cobertura vegetal são os itens que encerraram os procedimentos de base levados a efeito. Sobre esse tripé - revisão bibliográfica, trabalhos de campo e interpretação de imagens orbitais, se assentou o empenho de interpretação da vegetação e seu papel na composição da paisagem na área de estudo. Acessoriamente, foram realizadas coletas de solos para análise química (fertilidade + matéria orgânica) e física (granulometria), e de exemplares botânicos para identificação. Todos os pontos nos quais alguma coleta foi empreendida foram georreferenciados em GPS Garmin (modelo Etrex) e marcados nas folhas topográficas com escala de 1/50.000 (Lima Duarte, SF-23-X-C-VI-3; Bom Jardim de Minas, SF-23-X-C-V-4; Santa Bárbara do Monte Verde, SF-23-X-C-VI-4; Bias Fortes, SF-23-X-C-VI-1; Santana do Garambéu, SF-23-X-C-V-5), bem como nas imagens de satélite.

A classificação da cobertura vegetal utilizou-se das imagens de satélite TM-Landsat (composição de bandas 5, 4, 3 e 3, 2, 1) e do software ENVI 4.8, ambiente no qual se lançou mão da ferramenta Classificação Supervisionada, utilizando-se a amostragem dos pixels referentes a cada classe de uso e/ou ocupação da terra e cobertura vegetal. Foi gerado um mapa intermediário para auxílio nas campanhas de campo, posteriormente reinterpretado e reclassificado para a formatação e edição do mapa de uso e cobertura da terra apresentado em Marques Neto e outros (2014), aqui adaptado em sua legenda segundo os princípios da zonalidade/azonalidade de Isachenko (1973). Ainda, o mapa aqui apresentado sofreu melhoramentos possibilitados pelo uso da extensão ArcBrutile versão 0.3.3 (Bing Maps), anexada no ambiente do ArcMap $\left(E S R I{ }^{\circledR}\right)$ para digitalização manual de alguns arranjos vegetacionais que se encontram preservados nas áreas protegidas do Parque Estadual do Ibitipoca, e que foram objetos de mapeamento detalhado de Oliveira Filho e outros (2013), reconhecíveis mediante o zoom em alta precisão que o recurso supramencionado admite.

Juntamente a esses procedimentos, fizeram-se esforços para interpretar a estrutura superficial da paisagem a partir das coberturas de alteração mais recorrentes, no intuito de se estreitar as correlações entre as fitofisionomias e a natureza do substrato. Para tanto, foi elaborada uma carta de unidades pedológicas para toda a área do município e divulgada em publicação anterior (Marques Neto et al., 2014), aproveitando-se ainda de mapeamento levado a efeito por Rocha (2013) para a área do Parque Estadual do 
Ibitipoca e adjacências. Para fins de investigação de aspectos físico-químicos dos mantos de alteração e suas relações com a vegetação foram coletadas amostras de coberturas pedológicas sob campo e floresta, posteriormente encaminhadas ao laboratório de solos da Universidade Federal de Lavras, onde foram realizados ensaios de rotina. Os aspectos físicos se pautaram na definição das classes texturais arenosa (solo tipo 1), média (solo tipo 2) e argilosa (solo tipo 3). A química dos materiais superficiais foi contemplada nos seguintes parâmetros: $p H$ medido em água; matéria orgânica $(\mathrm{dag} / \mathrm{kg})$; acidez trocável (extrator cloreto de potássio); acidez potencial $\left(\mathrm{Al}^{3+}+\mathrm{H}^{+}\right.$, em extrator SMP); bases trocáveis, sendo o $\mathrm{Ca}$ e o $\mathrm{Mg}$ também obtidos pelo extrator $\mathrm{KCl}$ e o $\mathrm{Na}$ e $\circ \mathrm{K}$ pelo extrator Mehlich. A capacidade de troca catiônica (CTC), dada pela somatória da acidez potencial e das bases trocáveis, é calculada em condições de $\mathrm{pH} 7,0$, e a saturação por alumínio $(\mathrm{m})$ é definida pela divisão do alumínio trocável pela soma desse valor ao de bases multiplicado por 100. O reconhecimento e classificação dos solos também se valeram da descrição de perfis (Lemos; Santos, 1976) e do reconhecimento em campo das organizações estruturais ao longo de topossequências.

Ainda, foram reconhecidas e classificadas as espécies vegetais dominantes nos diferentes contextos pedológicos. Quando necessário, o material botânico foi coletado, prensado em campo, e encaminhado para identificação no herbário do Instituto de Biociências da Universidade Federal de Juiz de Fora.

\section{A área de estudo}

Lima Duarte se localiza na parte sudeste do estado de Minas Gerais (Figura 1), na região designada por Zona da Mata, conforme mencionado. Geologicamente, os terrenos em apreço estão embasados pelos metassedimentos da megassequência Andrelândia (Heilbron et al., 2004), diferenciando-se biotita-gnaisses emoldurando morros, morrotes e pequenas colinas mamelonizadas e tendencialmente convexas, e quartzitos que balizam cristas alongadas componentes de importantes patamares de cimeira regionais. As cristas quartzíticas correspondem aos setores do município contidos na Serra da Mantiqueira, enquanto os compartimentos de relevo mamelonizado se encontram nos terrenos pertencentes ao Planalto do Alto Rio Grande e ao Planalto dos Campos das Vertentes, em sua extremidade meridional, onde trunca as altas cristas da Mantiqueira.

As topografias mamelonares são revestidas por mantos de alteração profundos de textura argilosa a média, com pedogênese latossólica recorrente composta tanto por coberturas eluviais como por colúvios pedogeneizados, conspícuos nas baixas encostas. Sobre as coberturas superficiais argilosas ocorriam originalmente formações florestais típicas da zona da mata, cada vez mais fragmentada na região. As coberturas pedológicas relacionadas às cristas quartzíticas se referem a solos rasos, ácidos e pobres em bases trocáveis, ocorrendo cambissolos associados aos neossolo litólico, regolítico e quartzarênico, que dão aporte aos campos quartzíticos típicos destes geoambientes.

A ocorrência dos campos se vincula ao clima tropical de altitude que se consubstancia nos patamares de cimeira que chegam a se aproximar dos 1.500 metros de elevação, 
fundamentalmente nos compartimentos serranos responsáveis pela existência de considerável amplitude altimétrica no território municipal de Lima Duarte. Nas áreas mais rebaixadas aquém de 1.000 metros predomina o clima tropical típico, e as temperaturas médias são distintamente mais elevadas, a exemplo do que se verifica na própria sede municipal, erigida no fundo do vale do rio do Peixe em faixa altimétrica de 700 metros.

As atividades agropecuárias são restritas em Lima Duarte, e se processam principalmente nos compartimentos de morros e colinas na forma de pastagem. Circunstancialmente, o rebanho bovino é acomodado nos patamares mais baixos das serras Negra e de Lima Duarte, de constituição quartzítica, prática que vem deflagrando processos erosivos de monta em alguns locais. Além disso, as práticas de plantio se restringem à produção familiar e não ocupam grandes extensões, exceção feita à silvicultura de Eucalyptus que tem partilhado cada vez mais efetivamente da composição da paisagem.

\section{Figura 1}

Localização do município de Lima Duarte-MG

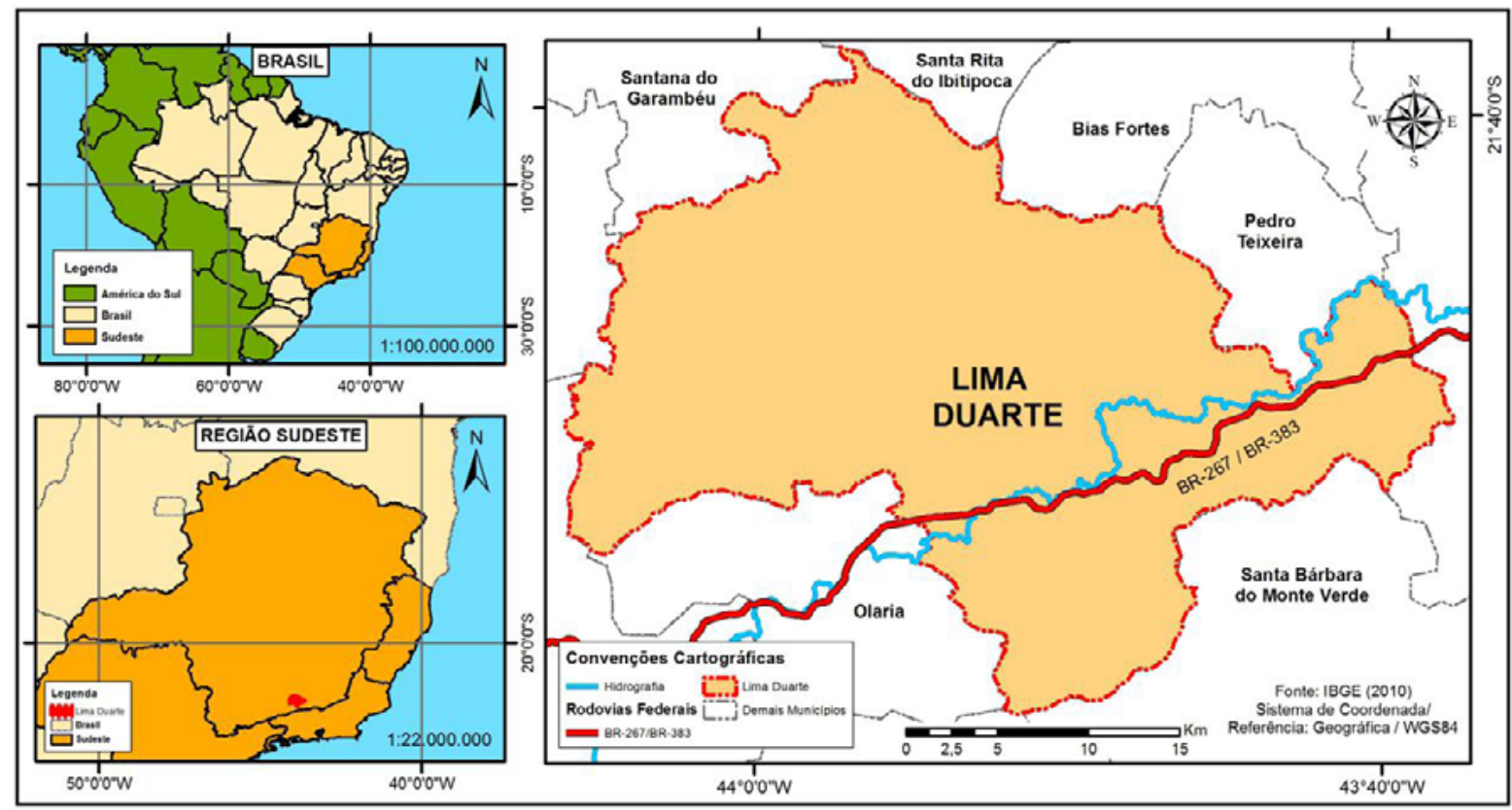

fonte: Marques Neto e outros (2014).

Ecossistemas zonais e enclaves: o significado fitogeográfico do território de Lima Duarte na conjunção campo/floresta

A influência mútua e recíproca entre elementos zonais e azonais na composição da paisagem em Lima Duarte foi uma premissa previamente estabelecida em função do que a própria paisagem revela. Os fatores zonais emergem da tropicalidade, e favorecem 
a vegetação florestal em coberturas argilo-siltosas derivadas da alteração de biotitagnaisses e xistos, coberturas estas pedogeneizadas em latossolos, solos de organização argilúvica e mesmo cambissolos; os componentes azonais tem eclosão sempre que os traços da tropicalidade são atenuados, sendo engendrados pelos altos topográficos mantenedores de solos rasos (neossolos litólicos, regolíticos e cambissolos) e arenosos produtos da alteração de quartzitos sobre os quais medram campos em variados arranjos fisionômicos. A princípio parece se definir uma configuração geoecológica que sugere certa polarização entre florestas sobre solos argilosos em gnaisse-granitos e campos sobre solos arenosos em quartzitos, impressão que deve ser descartada em prol da necessidade de interpretações de conexões mais detalhadas para a explicação da ocorrência das diferentes fitofisionomias florestais e de singulares campos em compartimentos intermontanos sobre solos maduros e argilosos que destoam dos contextos morfopedológicos com os quais as formações abertas campestres recorrentemente se inter-relacionam. Dessa forma, mosaicos complexos formados por diferentes agrupamentos vegetacionais e unidades de uso da terra se interdigitam na composição da paisagem em Lima Duarte (Figura 2).

\section{Figura 2}

Uso da terra e cobertura vegetal no município de Lima Duarte-MG

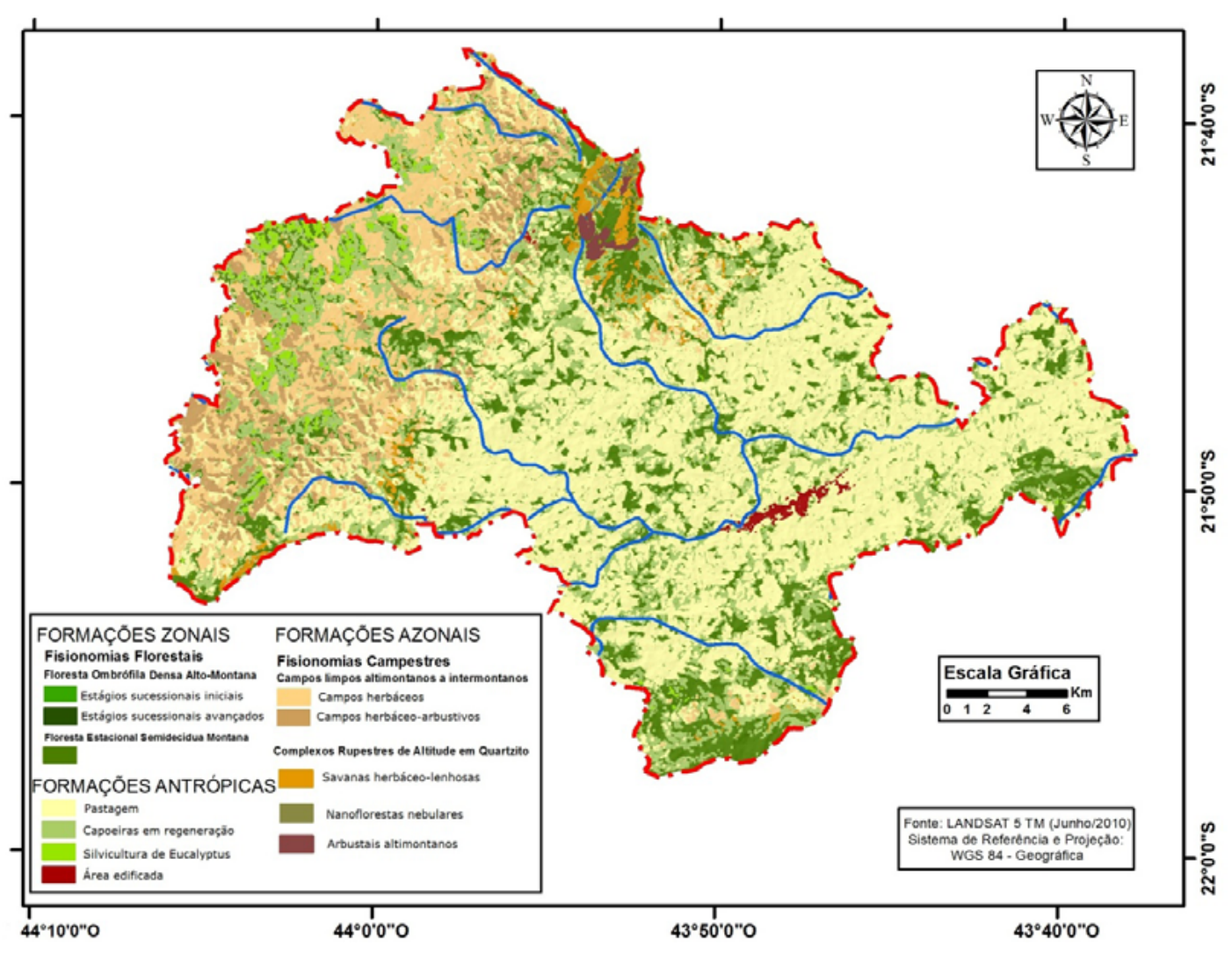


As florestas latifoliadas subsistem em extensões consideráveis ao longo das encostas serranas, originando corredores nos níveis mais elevados dos flancos declivosos da Serra Negra e de Lima Duarte, e que se projetam em direção a outros segmentos da Serra da Mantiqueira. Mais a norte, um estoque florestal ocorre nas vertentes escarpadas da Serra do Ibitipoca, onde as matas formam um cinturão abaixo dos campos rupestres que ocorrem nos patamares de cimeira, definindo-se uma fisionomia em floresta Ombrófila Densa Alto-Montana sobre coberturas argilosas produto da alteração em xistos, marcadamente pedogeneizada em cambissolos. Entre os dois compartimentos serranos a vegetação florestal ocorre sobre latossolos e assume caráter mais fragmentário, intercalando-se com áreas de vegetação rasteira onde predominam gramíneas exóticas aproveitadas para pastagem.

Pela classificação do IBGE (1992), adotada no presente trabalho para designação das fitofisionomias florestais, a maior parte das formações com comportamento ecofisiológico semidecidual constituem formações montanas, conforme aparece na legenda do documento cartográfico apresentado (Figura 2). Em Lima Duarte, as matas nebulares, do tipo ombrófila, ocorrem nas encostas mais elevadas da Serra de Ibitipoca e da Serra Negra, revelando uma forte influência do relevo na sua distribuição, condição que engendra certa continuidade para este grupo fisionômico. Na Serra de Lima Duarte é uma Floresta Estacional Semidecidual que emerge em suas vertentes orientadas para norte, se restringindo muitas vezes às rupturas de declive que separam os flancos escarpados de cimeira dos degraus reafeiçoados em interflúvios já tomados pela pastagem, atividade que exerce as pressões mais significativas na vegetação florestal remanescente.

Embora seja registrada na Serra de Lima Duarte, a Floresta Estacional Semidecidual ocorre de forma mais típica em coberturas argilosas de relevos mamelonizados emoldurados em litologia gnáissica que se posicionam nos domínios intermontanos entre as faixas interfluviais quartzíticas em pronunciada amplitude altimétrica. Nessas áreas, os condicionantes geomorfológicos não tem favorecido o estabelecimento de continuidades florestais da maneira que ocorre perseguindo os alinhamentos de cristas, apresentando estes grupos fisionômicos uma maior fragmentação e disjunção entre os remanescentes ladeados por áreas de pastagem.

AmaiorpartedasfitofisionomiasflorestaisocorrentesemLimaDuarte, enfaticamente as de Floresta Estacional Semidecidual, correspondem a áreas de mata secundária em distintos estágios sucessionais dados a partir de uma remoção ou alteração pretérita. Perfazem compartimentos de morros e de baixas serras, e apresentam de forma copiosa espécies pioneiras, como os gêneros Eremanthus, Tibouchina, Tabebuia, Piptadenia, Cassia e Cecropia, abundantes nas bordas destes fragmentos. As partes central e leste do município de Lima Duarte são consideráveis áreas em regeneração, e grande parte delas ocorre em sistemas de relevo acidentado, onde o trabalho de preparo da terra para práticas agrícolas é dispendioso do ponto de vista energético, desencorajando assim as atividades produtivas e reincorporando a vegetação nativa ao longo das últimas três ou 
quatro décadas, segundo a memória das comunidades locais. Presume-se, entretanto, que os estoques florestais existentes nas encostas serranas mais íngremes sejam de caráter primário, função dos acentuados declives inibidores de quaisquer formas de usos mais intensivos e da conspicuidade de espécies pertencentes aos estágios de sucessão mais avançados, com emergência de Ficus, Euterpe, Cariniana, Cedrela entre outros macrofanerófitos altos definidores de uma fisionomia que se mantém até a eclosão dos terrenos rupestres quartzíticos.

As fitofisionomias florestais tem ocorrência em coberturas formadas predominantemente por materiais de fina granulometria, com textura argilosa a média (Quadro 1). A ocorrência de corpos florestais se dá em solos imaturos (neossolos), mesomaduros (cambissolos) e bem desenvolvidos (latossolos e argissolos). Os solos analisados se demonstraram ácidos, pobres em bases (ainda que as taxas de potássio sejam consideráveis), assumindo uma natureza eminentemente distrófica, com índices de saturação por alumínio que superam aqueles dos campos. Esse quadro geoquímico se deve à natureza ácida das rochas matrizes, com intercalações de quartzito entre gnaisses e xistos leucocráticos, bem como à remoção de bases processada mediante lixiviação intensa em clima quente e úmido.

\section{Quadro 1}

\section{Aspectos físico-químicos de solos sob floresta}

\begin{tabular}{|c|c|c|c|c|c|c|}
\hline tipo de solo & UTM & $\begin{array}{c}\text { ALT. } \\
(\mathrm{m})\end{array}$ & $\begin{array}{c}\text { classe textural e } \\
\text { proporção argila/ } \\
\text { silte/areia (dag/kg) }\end{array}$ & SB & $\mathrm{m}$ & fitofisionomia \\
\hline latossolo & $617400 / 7582651$ & 729 & $\begin{array}{c}\text { textura argilosa } \\
52 / 16 / 32\end{array}$ & 0,23 & 79,65 & $\begin{array}{c}\text { floresta estacional } \\
\text { semidecidual }\end{array}$ \\
\hline latossolo & $627099 / 7581657$ & 1055 & $\begin{array}{c}\text { textura média } \\
22 / 5 / 73\end{array}$ & 0,40 & 75,00 & $\begin{array}{c}\text { floresta estacional } \\
\text { semidecidual }\end{array}$ \\
\hline cambissolo & $627315 / 7581657$ & 1117 & $\begin{array}{c}\text { textura média } \\
24 / 5 / 71\end{array}$ & 0,23 & 56,60 & $\begin{array}{c}\text { floresta estacional } \\
\text { semidecidual }\end{array}$ \\
\hline neossolo & $627315 / 7581657$ & 11175 & $\begin{array}{c}\text { textura média } \\
\text { litólico }\end{array}$ & $0,5 / 63$ & 62,10 & $\begin{array}{c}\text { floresta aberta } \\
\text { com candeias }\end{array}$ \\
\hline
\end{tabular}

legenda: SB - soma de bases; $m$ - índice de saturação por alumínio.

Embora a vegetação florestal componha a fisionomia regional dominante, elementos azonais são contundentes na composição dos geossistemas regionais; respondem a controles morfopedológicos e estruturais e à emergência do clima tropical de altitude, com forte influência do efeito Fohen/Chinock que ocorre pelas vertentes da Serra Negra e de Lima Duarte. Materializam-se assim interessantes enclaves ou redutos, na plena acepção de Ab'Sáber (2003), padronizadas em campos sobre solos rasos ou sobre substrato eminentemente rupestre. Esses arranjos perfazem os ambientes altimontanos, 
coroando mosaicos formados por extensões e fragmentos florestais intercalados a atividades rurais que tipificam os setores intermontanos e as terras mais baixas no fundo do vale do rio do Peixe.

As fitofisionomias campestres padronizam a cobertura vegetal nas serras quartzíticas, e são de grande valor biogeográfico. Sua ocorrência é atrelada ao quartzito, aparecendo vinculada a estas litologias no sul de Minas, Campo das Vertentes, região central, projetando-se a norte pela Serra do Espinhaço até a Bahia. A estas formações sui generis várias designações têm sido propostas e uma série de considerações tem sido feitas na literatura que discute a vegetação brasileira (Magalhães, 1966; Rizzini, 1979; Ferri, 1980; Semir, 1991; Einten, 1982; Benites et al., 2003; Vasconcelos, 2011; Marques Neto, 2014).

A presença de campos rupestres sobre as cristas quartzíticas define um importante patrimônio natural na região expresso por geodiversidade portentosa e biodiversidade digna de nota. Alinhamentos topográficos de exuberante beleza cênica são depositários de importantes endemismos que eclodem em um padrão de distribuição marcadamente disjunto no território brasileiro. As áreas de maior interesse conservacionista se referem, indubitavelmente, aos setores serranos, mantenedores que são de cinturões de Floresta Ombrófila Densa Alto Montana em suas vertentes escarpadas e de campos rupestres em seus somitais. Dutra; Salimena; Meinini Neto (2012), chamam a atenção para o caráter prioritário para a conservação na região da Serra Negra, dedicando considerações específicas à ocorrência da família Annonaceae, presente em três gêneros e sete espécies. Ainda, nos campos rupestres do compartimento supramencionado Abreu, Santiago e Menini Neto (2007) reconheceram cinco espécies pertencentes à família Orchidaceae que até então não haviam sido registradas no estado de Minas Gerais, duas delas (Maxillaria bradei e Pabstia jugosa) na porção da Serra Negra pertencente ao município de Rio Preto e que, em função da proximidade, é provável a ocorrência de tais espécies no município de Lima Duarte em locais de difícil acesso.

$\mathrm{Na}$ Universidade Federal de Juiz de Fora se desenvolve um projeto interessado em estudos botânicos na região da Serra Negra. A empresa científica em apreço conta com um sítio na internet (UFJF, [s.d]) encarregado de divulgar estudos voltados para a região em específico, além de disponibilizar um herbário virtual que aponta a presença de 119 famílias de angiospermas e das duas famílias de gimnospermas (Araucariaceae e Podocarpaceae) ocorrentes nas terras altas do Sudeste brasileiro, respectivamente as espécies Araucaria angustifolia e Podocarpus lamberti.

Os campos rupestres também ocorrem na Serra do Ibitipoca, resguardados em unidade de conservação de proteção integral (Parque Estadual do Ibitipoca), com conspicuidade de poáceas, veloziáceas, cactáceas, arbustos do gênero Microlicia e candeias (Eremanthus $s p$ ) como principais dominantes ecológicos. Espécies das famílias Orchidaceae e Bromeliaceae também são recorrentes, sendo esta familia registrada por Monteiro e Forzza (2008) em 11 gêneros e 32 espécies. As coberturas campestres na Serra de Ibitipoca não são uniformes, apresentando variadas sinúsias que guardam 
estreitas relações com a natureza do substrato (Figura 3), sendo que em ambientes eminentemente litólicos a diversidade vegetal é distintamente menor e as dominâncias ecológicas muito flagrantes, situação que se modifica com a ocorrência de solos rasos que possibilitam uma retenção mais eficiente de água e uma vegetação mais adensada e variada em espécies. Caracterização proficiente acompanhada de mapeamento e proposta de classificação para as associações vegetais diversas ocorrentes no Parque Estadual do Ibitipoca foram apresentadas por Oliveira Filho e outros (2013), que concebeu as seguintes categorias fitofisionômicas: floresta nebular, nanofloresta nebular, arbustal nebular, savana arbustivo-arbórea nebular e savana arbustiva nebular, campina lenhosa nebular e campina nebular, categorias estas subdividias segundo as condições ambientais ligadas ao relevo e substrato. Segundo os resultados apresentados pelos autores, as nanoflorestas aparecem vinculadas a fundos de vales e encostas mais servidas de umidade ou formando aureolas envolvendo as florestas nebulares e transicionando as passagens para os ambientes savanícolas e campestres. As savanas arbustivas e arbóreas e as campinas figuram como fitofisionomias que apresentam o aspecto campestre, sendo ainda discernidos os arbustais (scrubs), formações sem o aspecto fisionômico do campo, mas de um estrato arbustivo denso e emaranhado. As diferentes fisionomias ocorrentes nestes complexos em quartzito estão ligadas à diversidade de hábitat proporcionada pela presença de área protegida e pelo alargamento interfluvial verificado na extremidade norte da Serra do Itibipoca, que abre considerável expressão areolar nos patamares de cimeira, dissecados em padrão semicentrípeto convergente a um nível de base local, engendrado vertentes voltadas para diferentes direções, desiguais em iluminação, umidade, declive, forma e sistemas de transformação pedológica. A diversidade fisionômica relatada se deve a essa gama de influências se deve.

\section{Figura 3}

\section{Fitofisionomias no Parque Estadual do Ibitipoca}

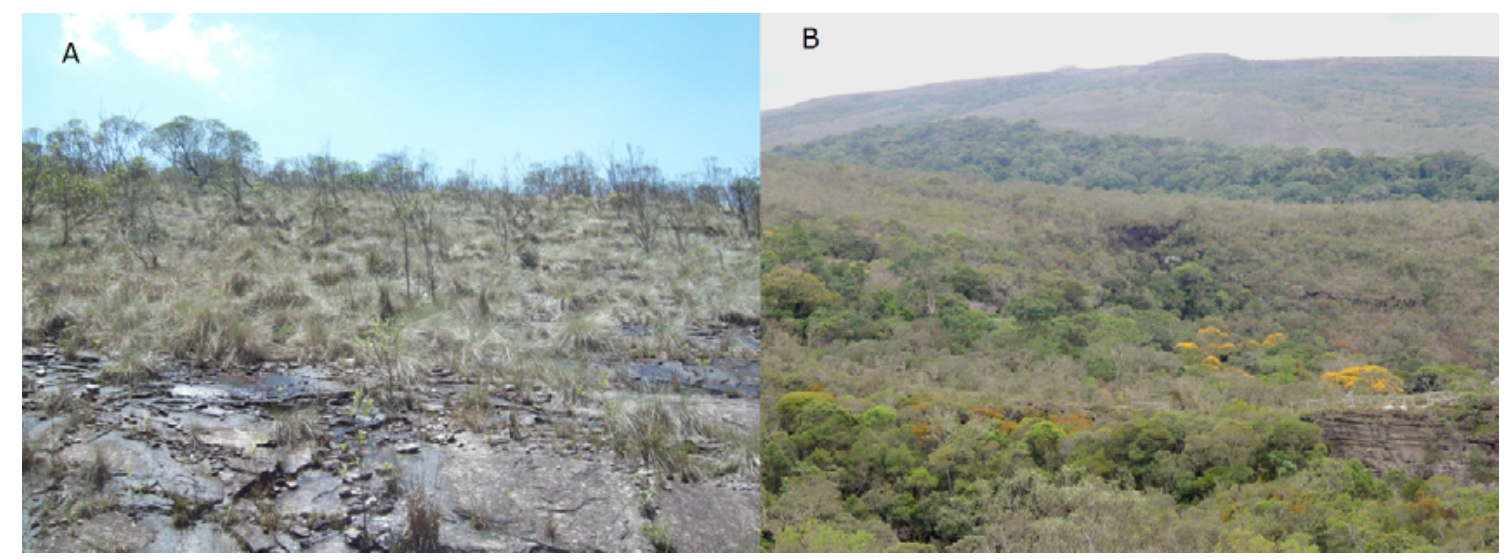

legenda: (A) campo rupestre com gramíneas de distribuição regular e massa lenhosa esparsa. (B) sucessão de fitofisionomias na Serra do Ibitipoca, com nanoflorestas em primeiro plano, e, na parte central da foto, vinculadas a depressões úmidas, intercaladas por campos rupestres em espigão local; ao fundo, nas cimeiras, campo limpo com predomínio de herbáceas. 
As fisionomias em campo limpo eclodem quando o substrato é formado por solos arenosos imaturos (Quadro 2) e areias quartzosas facilmente espalháveis pela ação hídrica e eólica, sendo bastante pobres em macronutrientes. Dias (2000) e Dias e outros (2002), embora acatem a diferenciação de campos rupestres para setores de afloramento e campo de altitude para setores providos de solo, também enxergam diferenças fisionômicas dadas pela espessura do solum e consequente diferenciação na capacidade de retenção hídrica. Espécies xeromórficas como as pertencentes à família das cactáceas aparecem nos ambientes litólicos, incidindo seu sistema radicular pelas falhas e diáclases presentes na estrutura quartzítica.

\section{Quadro 2}

Aspectos físico-químicos dos solos que aportam campos rupestres, substrato quartzito

\begin{tabular}{|c|c|c|c|c|c|c|}
\hline tipo de solo & UTM & $\begin{array}{c}\text { ALT. } \\
(\mathrm{m})\end{array}$ & $\begin{array}{c}\text { classe textural e } \\
\text { proporção argila/ } \\
\text { silte/areia }(\mathrm{dag} / \mathrm{kg})\end{array}$ & SB & $\mathrm{m}$ & fitofisionomia \\
\hline $\begin{array}{c}\text { Neossolo } \\
\text { Litólico }\end{array}$ & $616365 / 7577963$ & 1231 & $\begin{array}{c}\text { textura arenosa } \\
11 / 0 / 89\end{array}$ & 1,20 & 38,12 & campo rupestre \\
\hline $\begin{array}{c}\text { Neossolo } \\
\text { Litólico }\end{array}$ & $600514 / 7585115$ & 1034 & $\begin{array}{c}\text { textura arenosa } \\
13 / 11 / 76\end{array}$ & 1,46 & 25,51 & campo rupestre \\
\hline $\begin{array}{c}\text { Neossolo } \\
\text { Litólico }\end{array}$ & $610883 / 7598613$ & 1249 & $\begin{array}{c}\text { textura arenosa } \\
11 / 3 / 86\end{array}$ & 0,60 & 50,00 & campo rupestre \\
\hline \begin{tabular}{c} 
Cambissolo \\
\hline
\end{tabular} & $615846 / 7581082$ & 795 & textura arenosa \\
$43 / 4 / 53$ & 0,87 & 53,34 & campo rupestre \\
\hline
\end{tabular}

legenda: SB - soma de bases; $m$ - índice de saturação por alumínio.

Os campos rupestres em quartzito estão entre as formações campestres de mais notório reconhecimento, posto que se atrela diretamente a esta litologia em arranjos fitofisionômicos dos mais singulares, ainda que diferenciações florísticas sejam recorrentes ao longo das faixas quartzíticas dos cinturões móveis do território brasileiro em função das barreiras existentes e dos processos vicariantes conseguintes nas populações disjuntas, conforme afiançado por Messias e outros (2012). O apego edáfico dos campos rupestres não sugere que sua atual distribuição se deva unicamente a ciclos de expansão e contração durante as oscilações climáticas do Quaternário, sendo que sua disjunção deve ser bem antiga, e a distribuição das espécies estaria associada à sua capacidade 
de dispersão, enfaticamente levada a efeito por meio de polinização, estando, portanto, deveras atrelada ao comportamento dos organismos polinizadores (Rapini et al., 2008). Entretanto, nem todas as formações vegetais abertas de fisionomia campestre tem essa relação tão direta com o substrato.

\section{"Região dos campos": o mais interessante palimpsesto}

Os quartzitos não suportam o único geoambiente onde se tem a ocorrência de uma fitofisionomia campestre em Lima Duarte. Na parte oeste do município avultam outras fitofisionomias com franco predomínio do estrato herbáceo, que ocorre sobre coberturas de alteração mais profundas desenvolvidas em morros de encostas suavizadas a colinoso, com declives moderados e entalhe vertical menos pronunciado em comparação aos demais sistemas geomorfológicos ocorrentes na área de estudo. Chama-se a este contexto de paisagem, pela própria fala do povo, de região dos campos.

Nas proximidades da linha interfluvial separadora das bacias dos rios do Peixe e Grande, os alinhamentos da Serra da Mantiqueira comportam campos nas vertentes $\mathrm{N}$ e NW, com a mata aparecendo nos grotões côncavos. Eclodem fitofisionomias campestres pronunciadamente contrastantes em comparação às coberturas florestais que medram nas vertentes opostas. Nos topos destas faixas interfluviais, uma fisionomia de florestas abertas com candeias parece marcar a transição entre um setor florestal e uma zona de campos intermontanos de acentuada singularidade. A emergência de tais fisionomias tem lugar nas adjacências do distrito de São Domingos como referência leste, e adentram pelo sul ao longo da calha do rio Grande, compartimento no qual se confinam até coalescerem com os campos cerrados na região de Carrancas e Minduri, ou mesmo com os campos gerais remanescentes no Planalto dos Campos das Vertentes.

As associações vegetais existentes na região dos campos correspondem a um mosaico formado por campos limpos, campo sujo e campo rupestre que começa a aparecer, conforme frisado, a partir da linha divisória com a bacia do rio Grande e subsistem em patamares altimétricos pouco acima de 1.000 metros (Figura 4A). Curiosamente, esses campos não são exclusivamente altimontanos; embora ocorram nas linhas interfluviais, ocupam vastamente setores intermontanos e chegam ao fundo do vale que dá passagem ao rio Grande, perpassando diferentes contextos pedológicos. Quando no quartzito, avultam os campos rupestres típicos, dominantemente herbáceos em Neossolo Regolítico e gramíneo-lenhoso em Neossolo Litólico e afloramentos, substrato sobre o qual a candeia (Eremanthus sp) assume dominância. Quando em litologia gnáissica, ocorrem sobre materiais mais argilosos pedogeneizados em cambissolos e mesmo argissolos e latossolos (Quadro 3, fFigura 4B), com flagrante dominância dos gêneros Stachytarpheta (Verbenaceae) e Byrsonima (Malpighiaceae). 


\section{Quadro 3}

\section{Aspectos físico-químicos dos solos sob campos herbáceos e arbustivos}

\begin{tabular}{|c|c|c|c|c|c|c|}
\hline tipo de solo & UTM & $\begin{array}{c}\text { ALT. } \\
(\mathrm{m})\end{array}$ & $\begin{array}{c}\text { classe textural e } \\
\text { proporção argila/ } \\
\text { silte/areia (dag/kg) }\end{array}$ & $\mathrm{SB}$ & $\mathrm{m}$ & fitofisionomia \\
\hline $\begin{array}{c}\text { neossolo } \\
\text { regolítico }\end{array}$ & $594763 / 7588911$ & 1.082 & $\begin{array}{c}\text { textura média } \\
26 / 2 / 72\end{array}$ & 0,43 & 67,67 & $\begin{array}{c}\text { campo herbáceo- } \\
\text { arbustivo }\end{array}$ \\
\hline cambissolo & $599000 / 7585163$ & 1.103 & $\begin{array}{c}\text { textura argilosa } \\
42 / 16 / 42\end{array}$ & 0,47 & 51,55 & campo herbáceo \\
\hline argissolo & $598401 / 7584422$ & 1.110 & $\begin{array}{c}\text { textura argilosa } \\
\text { HA: } 38 / 10 / 52 \\
\text { HB: } 47 / 8 / 45\end{array}$ & $\begin{array}{c}0,38 \\
0,23\end{array}$ & $\begin{array}{c}51,28 \\
0,00\end{array}$ & campo herbáceo \\
\hline argissolo & $594197 / 7589063$ & 1.085 & $\begin{array}{c}\text { textura média } \\
\text { HA: } 29 / 3 / 62 \\
\text { HB: } 27 / 1 / 72\end{array}$ & $\begin{array}{c}0,40 \\
0,34\end{array}$ & $\begin{array}{c}63,64 \\
22,73\end{array}$ & $\begin{array}{c}\text { campo herbáceo- } \\
\text { arbustivo }\end{array}$ \\
\hline latossolo & $602030 / 7586149$ & 1.074 & $\begin{array}{c}\text { textura argilosa } \\
45 / 25 / 30\end{array}$ & 0,39 & 45,44 & $\begin{array}{c}\text { campo herbáceo- } \\
\text { arbustivo }\end{array}$ \\
\hline
\end{tabular}

legenda: SB - soma de bases; $\mathrm{m}$ - índice de saturação por alumínio.

\section{Figura 4}

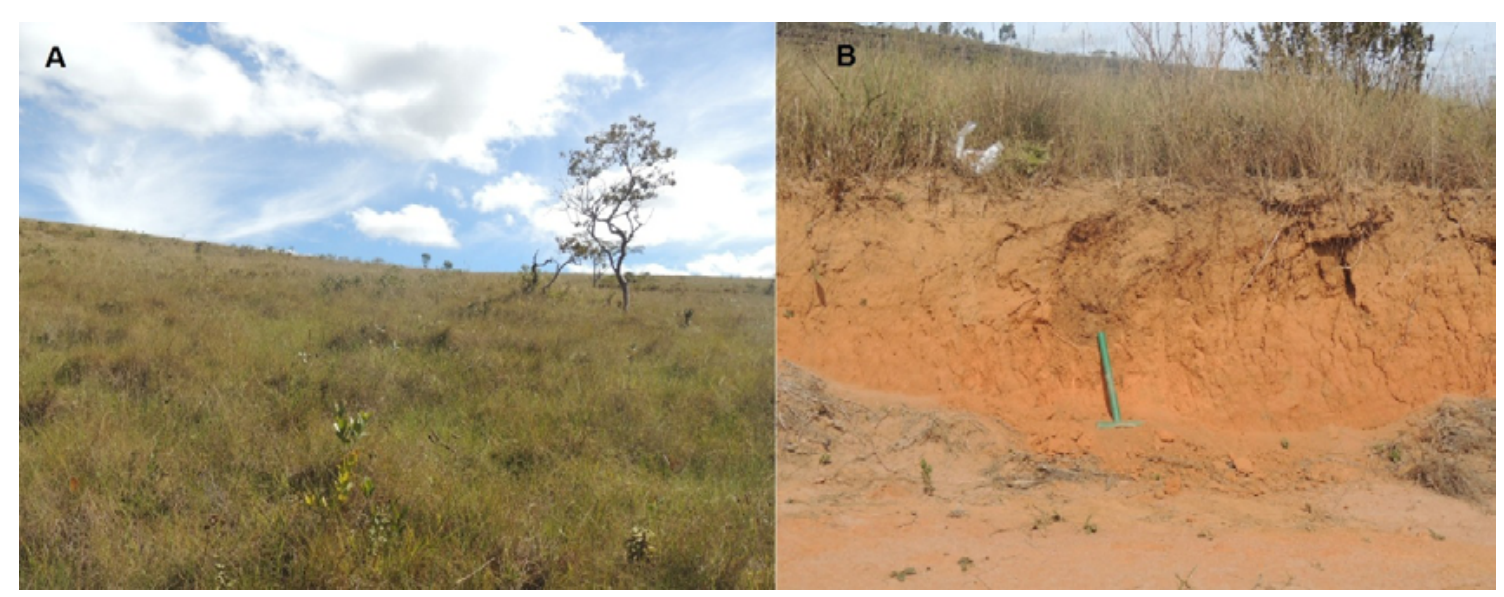

legenda: (A) fitofisionomia em campos herbáceo-arbustivos em domínios intermontanos; (B) ocorrência de campos graminosos sobre argissolos de textura argilosa média.

Algumas questões devem ser enfrentadas na interpretação destas formações vegetais. Sua ocorrência tem uma notória influência de cunho geomorfológico e estaria ligada à sua posição em uma calha elevada com temperaturas médias de clima tropical de altitude? Configuram relíquias paleoclimáticas que subsistem na condição de um mesorreduto, talvez favorecida por esta condição térmica hodierna? Obedecem a um controle edáfico consubstanciado por fatores limitantes do solo? Até que ponto se fazem correlacionáveis a outras formações de campo no centro-sul de Minas? 
Tão incomum é, no domínio tropical atlântico, a ocorrência de campos naturais em setores intermontanos e fundos de vale, que nos faz suspeitar que sua ocorrência esteja ligada a uma série de fatores ambientais conjugados. Em parte, a existência dos campos pode ser explicada pela compartimentação geomorfológica definida pela calha do rio Grande, que se abre acima de 1.000 metros, em altitude relativamente elevada para um compartimento de fundo de vale, o que provavelmente repercute em calhas induzidas e queda sensível das temperaturas médias. Além disso, o efeito orográfico levado a efeito pela Serra do Ibitipoca é considerável, o que repercute em volumes pluviométricos mais baixos nesse setor da calha do rio Grande na medida em que as massas úmidas são abduzidas por influência do alinhamento orográfico que caracteriza o divisor da margem direita. Essas influências orográficas no comportamento climático regional explicam parcialmente a presença de campos em áreas cuja altitude aporta, no contexto regional, fisionomias florestais. Essas condições ambientais podem ter resguardado as formações campestres intermontanas em condições de relíquias paleoclimáticas preservadas em domínios florestais do sul de Minas e da Zona da Mata, abaixo dos níveis altimétricos nos quais se encontram os atuais campos de altitude e nivelados altimetricamente às florestas. A hipótese de uma condição relicta de paleoclimas se reforça pela ocorrência destes campos em situações pedológicas incomuns para o tipo de vegetação em questão, amplamente distribuída em solos de organização argilúvica e mesmo latossolos, que no domínio tropical atlântico normalmente aportam vegetação florestal.

Em remissão ao Quadro 3, estes campos herbáceos e arbustivos ocorrem em diferentes tipos de solo, incluindo argissolos e latossolos cauliníticos, granulometricamente caracterizados por textura argilosa a média. Quimicamente, tais solos também são muito semelhantes aos de floresta, apresentando-se levemente ácidos, distróficos e bastante lixiviados, com teores significativos de potássio e baixas taxas dos demais macronutrientes básicos, configurando-se nesses materiais características típicas das coberturas de alteração tropicais. No entanto, as florestas não avançaram sobre esses terrenos com a perseverança da tropicalidade pós-glacial, e as fisionomias herbáceoarbustivas que aportam são inequivocamente nativas. Algumas coletas revelaram níveis de potássio e fósforo superiores aos ocorrentes nos solos sob floresta, com taxas similares de magnésio e cálcio, podendo ainda se apresentar ligeiramente menos ácidos e com saturação por alumínio um pouco mais baixa.

Oscampos constituemassimassinaturas de climas passados preservados na paisagem atual em posição topográfica e contexto pedológico tipicamente de floresta. Reforçando essa hipótese, observou-se que em algumas áreas de campo transformadas tem se instalado capoeiras lenhosas que sinalizam outra sucessão ecológica, provavelmente de caráter latifoliado, compatível com o contexto climatérico atual. Pelo que se observa, portanto, quando os campos são alterados ou removidos, não é uma nova vegetação de campo que tende a evoluir, o que constitui um forte fator de ameaça para estas fitofisionomias e para a integridade da paisagem de maneira geral.

A toponímia regional que designa este setor de Lima Duarte contido 
fundamentalmente na bacia do rio Grande é região dos campos, em referência direta a uma vegetação presente desde tempos imemoriais e que goza de forte apreço por parte da população. Existe, portanto, um profundo significado cultural dado a este patrimônio natural, ambos perigosamente corroídos pela silvicultura do eucalipto, que vem avançando pelos espaços rurais regionais como alternativa produtiva economicamente viável e mais vantajosa que as práticas tradicionais, avanço este que, na espacialidade de nosso interesse, tem se processado à custa de uma simplificação fenológica e florística acompanhada de notória e incômoda banalização destas singulares e interessantes paisagens campestres. $\mathrm{Na}$ linha divisória com a bacia do rio Grande, os reflorestamentos atingem os topos e suprimem perigosamente os referenciais fisionômicos contínuos dos campos, como se vê na Figura 2. Dispostos basicamente em orientação norte-sul, os eucaliptais cortam perpendicularmente as campinas nativas que se localizam na porção oeste de Lima Duarte e comprometem perigosamente sua continuidade. As assinaturas humanas nessas paisagens cuja retrospecção remete ao Pleistoceno, da maneira que vem sendo levadas a efeito nos tempos atuais, tendem a favorecer um rumo evolutivo mais atrelado à tropicalidade nos termos das sucessões ecológicas e sínteses bioquímicas vigentes, adequando-se ainda ao ritmo das sociedades humanas envolvidas e suas diferentes lógicas econômicas e conservacionistas, e que tem na silvicultura de eucalipto a prática econômica da vez.

\section{Considerações finais}

Os enclaves de campo que ocorrem na Zona da Mata também aparecem em outras regiões do Sudeste brasileiro, podendo chegar bem perto da fachada atlântica, como acontece com aqueles da Serra da Bocaina, ou mesmo nos domínios da Serra da Mantiqueira de São Paulo e sul de Minas Gerais. Especificamente, em Lima Duarte se organiza um traçado fitogeográfico no qual os campos dos compartimentos altimontanos são fundamentalmente rupestres e ocorrem nos domínios litológicos quartzíticos, ao passo que em vastos espaços intermontanos espalham-se campos limpos herbáceos ou fisionomias herbáceo-arbustivas, além dos tipos rupestres, sempre que o quartzito aflora em suas intercalações com xistos e gnaisses. Os campos rupestres são formações vegetais eminentemente edáficas que eclodem no substrato quartzítico sobre a própria rocha ou coberturas de alteração arênicas e mal desenvolvidas; por sua vez, os demais tipos campestres são formações paleoclimáticas, sobrando em solos argilosos desenvolvidos sobre os quais as florestas dominantes na região não avançaram no fim do último estágio glacial. Consubstancia-se dessa maneira um arranjo vegetacional complexo formado por formações climáticas de caráter zonal, dadas pelas fisionomias florestais, comunidades eminentemente edáficas azonais (campos rupestres), além das fisionomias de significado paleoclimático.

A ocorrência dos campos limpos extravasa muito o território de Lima Duarte, estendendo-se para o município limítrofe de Santana do Garambéu até Andrelândia, onde progressivamente dão passagem a campos cerrados à medida que se interioriza $e$ 
adentra os corredores transicionais. Nesse sentido, os campos estabelecem uma clara ligação entre a zona florestal da fachada atlântica e o cerrado pela calha do rio Grande em demanda a compartimentos planálticos do sul de Minas e Campos das Vertentes, assumindo assim importância valiosa na interpretação da evolução regional da vegetação na interface floresta/cerrado. Indiferente a tamanha importância, em todas as extensões de ocorrência dos campos, a monocultura de Eucalyptus é o principal fator de ameaça, tendo ganhado consideráveis áreas cobertas originalmente pelos campos. A conservação dessas formações vegetais sui generis deve ser tida como pauta permanente e ter respaldo estatutário, dado o caráter de exceção dessas paisagens ainda pouco estudadas no contexto da Zona da Mata Mineira e sul de Minas Gerais. Além disso, essas áreas são estratégicas nos fluxos gênicos permutados entre Mata Atlântica e cerrado, uma vez que se projetam como importantes faixas de tensão ecológica pelas quais elementos biogeográficos dos dois domínios tendem a se interpenetrar. Esse desafio depende de um planejamento ambiental regional e integrado que reconheça e considere as relações entre os campos, os ecossistemas florestais e os agrossistemas dominantes, considerando as permutas de matéria, energia e informação entre essas unidades, explorando as perspectivas de conectividade com os corredores ecológicos da Serra da Mantiqueira e introduzindo valores ambientais.

\section{Referências}

AB'SÁBER, A. N. Brasil: paisagens de exceção: o litoral e o pantanal mato-grossense: patrimônios básicos. Cotia, SP: Ateliê, 2006.

. Os domínios de natureza do Brasil: potencialidades paisagísticas. São Paulo: Ateliê, 2003.

Potencialidades paisagísticas brasileiras. Geomorfologia, n. 55, p. 1-28, 1977.

ABREU, N. L.; SANTIAGO, A. L.; MENINI NETO, L. Novos registros de Orchidaceae para a flora do estado de Minas Gerais, Brasil. Orchidstudium - International Journal of Orchid Study, v. 2, n. 2-3, p. 37-40, 2007.

BENITES, V. M. et al. Solos e vegetação nos complexos rupestres de altitude da Mantiqueira e do Espinhaço. Floresta e Ambiente, Seropédica-RJ, v. 10, n. 1, p. 76-85, 2003.

BERTALANFFY, L. V. Teoria geral dos sistemas. Petrópolis-RJ: Vozes, 1973.

CAVALCANTI, L. C. S. Da descrição de áreas à teoria dos geossistemas: uma abordagem epistemológica sobre sínteses naturalistas. Tese (Doutorado em Geografia) - Centro de Filosofia e Ciências Humanas, Universidade Federal de 
Pernambuco, Recife, 2013.

DIAS, H. C. T. et al. Geoambientes no Parque Estadual do Ibitipoca, município de Lima

Duarte-MG. Revista Árvore, v. 26, n. 6, p. 777-786, 2002.

Geoambientes e pedogênese no Parque Estadual do Ibitipoca, município de

Lima Duarte-MG. Tese (Doutorado em Solos e Nutrição de Plantas) - Departamento de Solos, Universidade Federal de Viçosa, Viçosa, 2000.

DUTRA, S. M.; SALIMENA, F. R. G.; MEININI NETO, L. Annonaceae na Serra Negra, Minas Gerais, Brasil. Rodriguésia, Rio de Janeiro, v. 36, n. 4, p. 785-793, 2012.

FERRI, M. G. Vegetação brasileira. São Paulo: Edusp, 1980.

HEILBRON, M. et al. Província Mantiqueira. In: MANTESSO NETO, V. et al. (Org.). Geologia do continente sul-americano: evolução da obra de Fernando Flávio Marques de Almeida. São Paulo: Beca, 2004. p. 203-234.

IBGE. INSTITUTO BRASILEIRO DE GEOGRAFIA E ESTATÍSTICA. Manual técnico da vegetação brasileira. Rio de Janeiro: IBGE, 1992. (Série Manuais Técnicos em Geociências, 1).

ISACHENKO, A. G. Principles of landscape science and Physical Geography Regionalization. Carlton: Melbourne, 1973.

LEMOS, R. C.; SANTOS, R. D. Manual de método de trabalho de campo. Campinas-SP: SBCS, 1976.

MAGALHÃES, G. M. Sobre os cerrados de Minas Gerais. Anais da Academia Brasileira de Ciências, v. 38, p. 59-70, 1966.

MARQUES NETO, R. Biogeografia dos complexos rupestres de altitude em quartzito no sul de Minas Gerais. Geografia, v. 39, n. 3, p. 511-523, 2014.

et al. Estrutura e dinâmica da paisagem no município de Lima Duarte-MG: uma abordagem geoecológica. Caminhos de Geografia, v. 15, n. 52, p. 134-150, 2014.

MESSIAS, M. C. T. B. et al. Fitossociologia de campos rupestres quartzíticos e ferruginosos do Quadrilátero Ferrífero, Minas Gerais. Acta Botanica Brasilica, v. 26, n. 1, p. 230-242, 2012. 
MONTEIRO, R. F; FORZZA, R. C. A família Bromeliaceae no Parque Estadual do Ibitipoca, Minas Gerais, Brasil. Bol. Bot. Univ. de São Paulo, São Paulo, v. 26, n. 1, p. 7-33, 2008.

OLIVEIRA FILHO, A. T. et al. O mosaico de fitofisionomias do Parque Estadual do Ibitipoca. In: FORZZA, R. C. et al. (Org.). Flora do Parque Estadual do Ibitipoca e seu entorno. Juiz de Fora, MG: Editora da UFJF, 2013. p. 53-93.

RAPINI, A. etal. AfloradoscamposrupestresdaCadeiadoEspinhaço. Megadiversidade, v. 4, n. 1-2, p. 15-23, 2008.

RIZZINI, C. T. Tratado de fitogeografia do Brasil. São Paulo: Hucitec, 1979.

ROCHA, G. C. O meio físico da região de Ibitipoca: características e fragilidade. In: FORZZA, R. C. et. al. (Org.). Flora do Parque Estadual do Ibitipoca e seu entorno. Juiz de Fora, MG: Editora da UFJF, 2013. p. 27-52.

SEMIR, J. Revisão taxonômica de Lychnophora Mart. (Vernoniacea: compositae). Tese (Doutorado em Biologia Vegetal) - Instituto de Biologia, Universidade Estadual de Campinas, Campinas, 1991.

UFJF. UNIVERSIDADE FEDERAL DE JUIZ DE FORA. Projeto Floresta Negra, [s.d]. Disponível em: http://www.ufff.br/florestanegral. Acesso em: 29 nov. 2015.

VALENTE, A. S. M.; GARCIA, P. O.; SALIMENA, F. R. G. Zona da mata mineira: aspectos fitogeográficos e conservacionistas. In: PAULA, A. P; OLIVEIRA, L. (Org.) Arqueologia e patrimônio da zona da mata mineira. Juiz de Fora, MG: Editar, 2006. p. 79-91.

VASCONCELOS, M. F. O que são campos rupestres e campos de altitude nos topos de montanha do Leste do Brasil? Revista Brasileira de Botânica, v. 34, n. 2, p. 241-246, 2011.

WALTER, H. Vegetação e zonas climáticas. 5. ed. São Paulo: EPU, 1984. 